This article was downloaded by: [The University of Manchester Library] On: 17 September 2012, At: 04:21

Publisher: Psychology Press

Informa Ltd Registered in England and Wales Registered Number: 1072954

Registered office: Mortimer House, 37-41 Mortimer Street, London W1T 3J H, UK

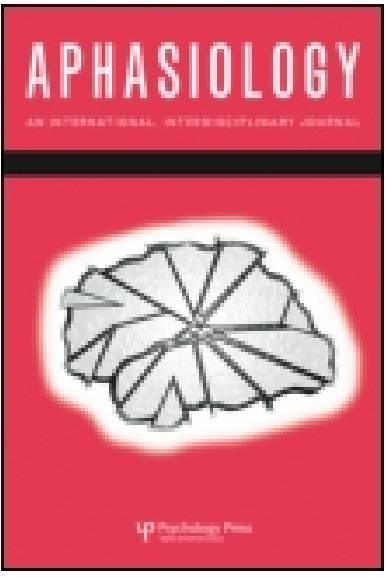

\title{
Aphasiology
}

Publication details, including instructions for authors and subscription information:

http:// www. tandfonline.com/loi/paph20

\section{Posterior middle temporal gyrus is involved in verbal and non-verbal semantic cognition: Evidence from rTMS}

Paul Hoffman ${ }^{a}$, Gorana Pobric ${ }^{a}$, Mark Drakesmith ${ }^{a} \&$ Matthew A. Lambon Ralph ${ }^{\text {a }}$

${ }^{a}$ Neuroscience and Aphasia Research Unit (NARU), University of Manchester, Manchester, UK

Version of record first published: 22 Sep 2011.

To cite this article: Paul Hoffman, Gorana Pobric, Mark Drakesmith \& Matthew A. Lambon Ralph (2012): Posterior middle temporal gyrus is involved in verbal and non-verbal semantic cognition: Evidence from rTMS, Aphasiology, 26:9, 1119-1130

To link to this article: http:// dx.doi.org/ 10.1080/ 02687038.2011.608838

\section{PLEASE SCROLL DOWN FOR ARTICLE}

Full terms and conditions of use: http://www.tandfonline.com/page/terms-andconditions

This article may be used for research, teaching, and private study purposes. Any substantial or systematic reproduction, redistribution, reselling, loan, sub-licensing, systematic supply, or distribution in any form to anyone is expressly forbidden.

The publisher does not give any warranty express or implied or make any representation that the contents will be complete or accurate or up to date. The accuracy of any instructions, formulae, and drug doses should be independently verified with primary sources. The publisher shall not be liable for any loss, actions, claims, proceedings, demand, or costs or damages whatsoever or howsoever caused arising directly or indirectly in connection with or arising out of the use of this material. 


\title{
Posterior middle temporal gyrus is involved in verbal and non-verbal semantic cognition: Evidence from rTMS
}

\author{
Paul Hoffman, Gorana Pobric, Mark Drakesmith, \\ and Matthew A. Lambon Ralph
}

\author{
Neuroscience and Aphasia Research Unit (NARU), University of Manchester, \\ Manchester, UK
}

\begin{abstract}
Background: Left posterior middle temporal gyrus (pMTG) is reliably activated in functional neuroimaging studies of semantic processing and is frequently damaged in patients with comprehension impairments following stroke (e.g., Wernicke's aphasia). Its precise function remains elusive, however. Some researchers take the view that pMTG is a multimodal semantic area, involved in verbal and non-verbal semantic cognition. Others ascribe a lexical-semantic function to the region, positing that it is involved in mapping between phonology and conceptual knowledge.

Aims: We investigated whether pMTG was involved in non-verbal as well as verbal semantic cognition by using rTMS to induce temporary, focal "virtual lesions" to this region in healthy participants.

Methods \& Procedures: Participants completed picture and word versions of a semantic association test before and after receiving 10 minutes of $1-\mathrm{Hz}$ offline rTMS to left pMTG. They also completed a difficulty-matched visual decision task on scrambled pictures. An occipital lobe control site was stimulated in a separate session.

Outcomes \& Results: TMS slowed responses to word and picture versions of the test to an equal degree. There was no slowing on a non-semantic visual-matching task, or following TMS to the control site.

Conclusions: These results indicate that pMTG is involved in both verbal and non-verbal semantic cognition. This region could be key to understanding the multimodal semantic deficits often observed following stroke.
\end{abstract}

Keywords: Conceptual knowledge; Semantic memory; Transcranial magnetic stimulation; Temporal lobe.

The left posterior middle temporal gyrus (pMTG) undoubtedly plays an important role in semantic cognition. It is one of the most reliably activated areas in functional imaging studies of semantic processing, as confirmed by its consistent appearance in meta-analyses of the neuroimaging literature on semantic cognition (Binder, Desai, Graves, \& Conant, 2009; Cabeza \& Nyberg, 2000; Indefrey \& Levelt, 2004; Vigneau et al., 2006). It is also frequently damaged in patients with comprehension deficits

Address correspondence to: Dr Paul Hoffman, Neuroscience and Aphasia Research Unit (NARU), Zochonis Building, School of Psychological Sciences, University of Manchester, Oxford Road, Manchester, M13 9PL, UK. E-mail: paul.hoffman@manchester.ac.uk

The research was supported by an MRC programme grant (G0501632) and an NIHR senior investigator award to MALR.

(C) 2012 Psychology Press, an imprint of the Taylor \& Francis Group, an Informa business http://www.psypress.com/aphasiology

http://dx.doi.org/10.1080/02687038.2011.608838 
(Chertkow, Bub, Deaudon, \& Whitehead, 1997; Hart \& Gordon, 1990; Noonan, Jefferies, Corbett, \& Lambon Ralph, 2010), with a large-scale lesion overlap analysis of 65 chronic patients identifying this region, rather than classical Wernicke's area (i.e., posterior superior temporal gyrus and sulcus), as critical for single-word comprehension (Dronkers, Wilkins, Van Valin, Redfern, \& Jaeger, 2004). Despite the broad consensus on the importance of pMTG in semantic processing, a number of conflicting proposals have been put forward regarding its function. One school of thought holds that pMTG is important for mapping between the phonological forms of words and their meanings (Hickok \& Poeppel, 2004, 2007; Indefrey \& Levelt, 2004; Turken \& Dronkers, 2011). On this view, pMTG acts as an interface between the auditoryphonological processing systems of Wernicke's area and semantic representations, which are thought to involve a number of distributed temporal lobe sites, including the anterior temporal lobes (Binder et al., 2009; Martin, 2007; Patterson, Nestor, \& Rogers, 2007; Visser, Jefferies, \& Lambon Ralph, 2010). This theory assigns pMTG a specific role in lexical-semantic processing, with no necessary involvement in nonverbal semantic cognition (e.g., object recognition, object use or comprehension of non-verbal sounds).

An alternative view is that pMTG is involved in semantic processing for both verbal and non-verbal stimuli. For example, many neuroimaging studies have reported that pMTG is strongly activated when retrieving knowledge of tools, leading to claims that pMTG is involved in the semantic representation of motion and actions (Devlin et al., 2002; Martin, 2007; Tranel, Martin, Damasio, Grabowski, \& Hichwa, 2005). Importantly, pMTG activation is found for entirely non-verbal tasks, such as judgements about the functions and actions associated with pictured objects (Kellenbach, Brett, \& Patterson, 2003) or matching pictures based on conceptual similarity (Kable, Lease-Spellmeyer, \& Chatterjee, 2002). These findings suggest that pMTG is involved in aspects of the core conceptual representation of objects, rather than the linking between conceptual knowledge and the phonological representations of words.

A third possibility is that pMTG is involved in the executive control process that regulate access to conceptual knowledge (Jefferies \& Lambon Ralph, 2006; Noonan et al., 2010; Whitney, Kirk, O’Sullivan, Lambon Ralph, \& Jefferies, 2011). Although these control functions have been traditionally associated with inferior prefrontal regions (e.g., Badre \& Wagner, 2007), neuroimaging studies have clearly demonstrated that activation in pMTG also varies with the control demands of semantic processing (Badre, Poldrack, Pare-Blagoev, Insler, \& Wagner, 2005; Bedny, McGill, \& ThompsonSchill, 2008; Gold et al., 2006; Noppeney, Phillips, \& Price, 2004; Rodd, Davis, \& Johnsrude, 2005; Whitney, Jefferies, \& Kircher, 2011). For example, Thompson-Schill, D'Esposito, Aguirre, and Farah's (1997) seminal fMRI study of semantic selection demands revealed substantial activation in pMTG when participants selected among competing alternatives, in addition to the inferior prefrontal region that was the focus of the paper. More recently, Rodd et al. (2005) observed greater pMTG activation for comprehension of sentences containing ambiguous words (e.g., "the shell was fired towards the tank") relative to matched sentences with no such ambiguity. Ambiguous words are thought to require greater executive control because of the need to select the context-appropriate meaning of the word from all of its possible uses. It is unclear whether this control function is present for non-verbal as well as lexical stimuli, as very few imaging studies to date have manipulated control demands in a non-verbal semantic task. 
In differentiating between these various functions, an important first step is to determine whether pMTG is implicated in non-verbal semantic cognition as well as lexical-semantic processing. On the surface, observations of pMTG activation for purely non-verbal semantic tasks appear to provide a conclusive answer to this question, but there are alternative interpretations. It has been noted by many researchers that activations in functional neuroimaging studies do not distinguish between regions that make a necessary contribution to the cognitive process of interest and those that are activated incidentally (e.g., Price \& Friston, 2002). In this case one possibility is that when a picture of an object is processed its name is automatically retrieved, even if the judgement being made does not require any lexical processing. In this scenario pMTG activation could reflect the automatic name retrieval that occurs as a by-product of recognising the objects, rather than indicating a true role in multimodal semantic cognition.

Lesion studies do not suffer from this limitation: lesions to pMTG should only produce non-verbal semantic deficits if the function of this region is essential for non-verbal semantic processing. However, while there are a number of reports of non-verbal semantic deficits following pMTG damage, lesions to this area are usually accompanied by damage to bordering regions. Hart and Gordon (1990) identified three patients with pMTG damage who had multimodal semantic deficits, although their lesions also encompassed the adjacent superior temporal and inferior parietal cortex. Chertkow et al. (1997) found deficits on non-verbal semantic tasks in five of eight patients with verbal comprehension impairments. While the patients with multimodal deficits had damage to pMTG, which was not present in those with purely verbal impairments, posterior superior temporal and inferior parietal cortices were also affected. Finally, some patients with multimodal deficits in control and regulation of semantic knowledge (Corbett, Jefferies, Ehsan, \& Lambon Ralph, 2009; Jefferies \& Lambon Ralph, 2006; Noonan et al., 2010) have damage to pMTG, although this damage extends into inferior parietal cortex and the superior occipitotemporal region (BA37). Superior temporal cortex is heavily involved in verbal and non-verbal auditory processing (e.g., Leff et al., 2009; Saygin, Dick, Wilson, Dronkers, \& Bates, 2003; Wise et al., 2001) and occipitotemporal cortex is implicated in high-level visual processing (e.g., Devlin, Jamison, Gonnerman, \& Matthews, 2006; Kherif, Josse, \& Price, 2011). As such, one possibility is that deficits on semantic tasks in these cases are due to perceptual impairments rather than genuine deficits in conceptual knowledge.

In the present study we used repetitive TMS (rTMS) to induce temporary "virtual lesions" in the left pMTG of healthy volunteers, and measured the effects on semantic association judgements for words and pictures. TMS produces focal stimulation that can be targeted at a precise area of cortex, avoiding the localisation problems in the neuropsychological literature. Moreover, a behavioural effect of TMS should only occur if the stimulated region is actively contributing to task performance. An additional benefit of rTMS is that performance in stimulated and non-stimulated conditions can be compared within the same healthy participants, which avoids effects of functional reorganisation that can occur in chronic brain injury (Walsh \& Cowey, 2000). As in previous TMS studies of semantic processing (Gough, Nobre, \& Devlin, 2005; Pobric, Jefferies, \& Lambon Ralph, 2007, 2010a, 2010b) we measured both accuracy and reaction times but expected the relatively subtle effects of stimulation to be manifested as a slowing in reaction times, rather than an increase in error rates. 


\section{METHOD}

\section{Participants}

A total of 14 staff and students from the University of Manchester took part ( 9 male; mean age $=21.1$ ). All were right-handed, native English speakers. They had no history of neurological disease or mental illness and had normal or corrected-tonormal vision. All gave written informed consent and the experiment was reviewed and approved by the local ethics board. Participants were reimbursed for their participation.

\section{Design}

A $2 \times 3 \times 2$ repeated-measures design was used, with site (left posterior middle temporal gyrus (pMTG) vs occipital pole), task (word semantic association vs picture semantic association vs pattern matching), and TMS (pre-TMS vs post-rTMS stimulation) as the three within-participants factors. We used the "virtual lesion" stimulation method in which a baseline level of behavioural performance is first obtained, then rTMS is delivered offline (with no concurrent behavioural task) and behavioural performance is probed immediately following stimulation during the temporary refractory period induced by the TMS. In pilot studies we have found that rTMS and the associated novel experience, irrespective of site of stimulation, can be highly alerting for participants and can produce a non-specific speeding in reaction times (Holland \& Lambon Ralph, 2010). To control for any non-specific alerting effects we employed both a non-semantic control task (pattern matching) and a control stimulation site (occipital pole). In each session, each participant received stimulation to either pMTG or the control site, with the order counterbalanced across participants. Sessions were separated by an interval of at least 1 week.

\section{Stimuli}

Participants completed two semantic association tasks (words and pictures) and two visual control tasks (see Figure 1). The semantic tasks were created by combining trials from the Pyramids and Palm Trees test (PPT; Howard \& Patterson, 1992) and the Camel and Cactus Test (Bozeat, Lambon Ralph, Patterson, Garrard, \& Hodges, 2000). We supplemented these with 10 items from another semantic association task to give a total of 120 word and 120 picture stimuli. In order to maintain a two-choice format over the entire test, two of the three foils were discarded from each trial of the CCT. Stimuli for the visual matching control task were created by scrambling the picture and word images using the Java Runtime Environment (www.SunMicrosystems.com). Pictures were divided into 80 pieces and words into 15 pieces and these were re-assembled at random.

\section{Procedure}

A PC running with a 15-inch monitor and E-Prime software (Psychology Software Tools Inc., Pittsburgh, USA) controlled the presentation of stimuli and recording of the responses. Participants completed two sessions and performed all four experimental tasks twice in each session. Each session began with a series of practice trials for all 

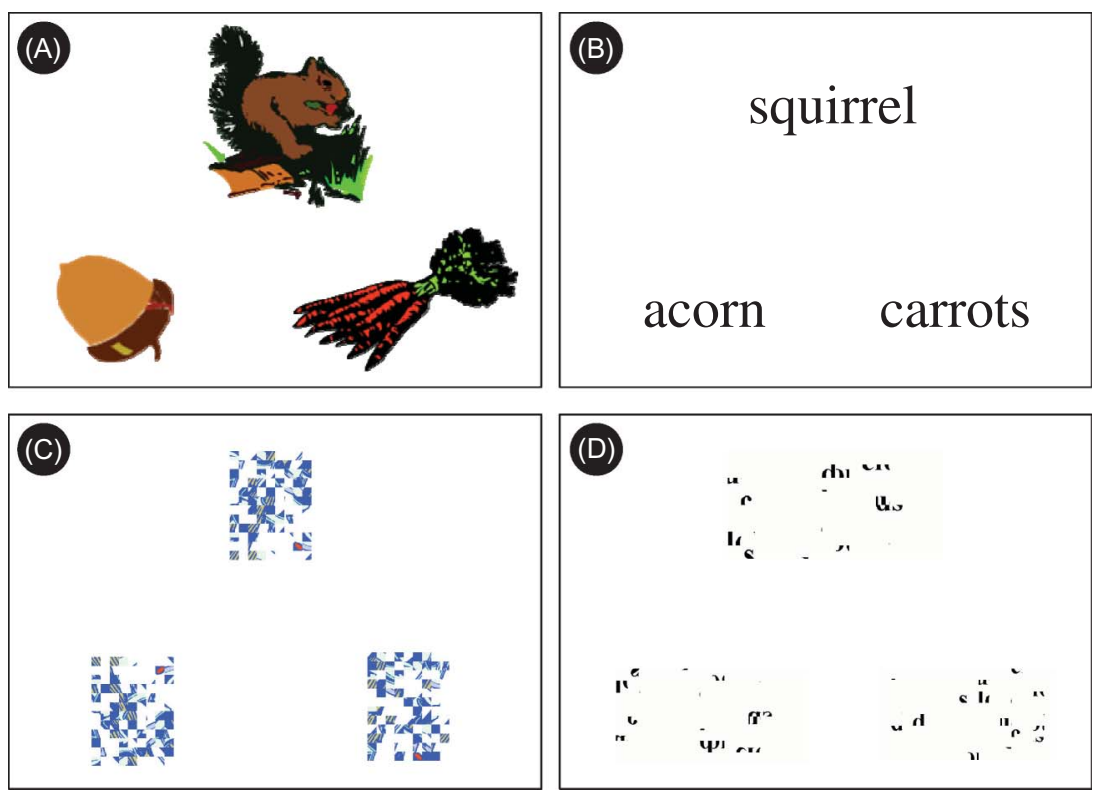

Figure 1. Experimental tasks. (A) and (B) show picture and word semantic association tasks and (C) and (D) show the corresponding mirror-image matching tasks. To view this figure in colour, please see the online issue of the journal.

four tasks, followed by pre-TMS task performance, 10 minutes of rTMS (see below), and post-TMS task performance.

In a single session participants saw all 120 trials from the combined PPT/CCT set, half as pictures and the remaining half as words. This order was counterbalanced across stimulation sites. There was no repetition of stimuli within a session but, across sessions, each trial was seen once in verbal and once in pictorial form. Experimental trials were presented in a random order in four blocks of 30 trials (pictures, words, scrambled pictures, and scrambled words). All blocks were randomised across participants. A fixation point appeared on the screen for $500 \mathrm{~ms}$ to signal the start of each trial. Stimuli were presented until response or for a maximum of $3000 \mathrm{~ms}$ followed by a blank screen interval of $500 \mathrm{~ms}$. In semantic association trials participants were shown a probe picture/word and two choice and indicated which of the two choice stimuli was more closely related to the probe (see Figure 1). In the pattern-matching task participants were presented with three scrambled images and they had to indicate which of the two choice patterns was a mirror image of the probe. Pilot testing indicated that this demanding visual task yielded reaction times comparable to the semantic tasks. Participants indicated responses by pressing with the right hand one of two designated keys on a keyboard.

\section{Anatomical MRI acquisition}

Stimulation sites were selected using 3D anatomical images acquired using a 3T Philips MR Achieva scanner (Philips Electronics, The Netherlands). MRI scanning parameters included a slice thickness of $0.9 \mathrm{~mm}$, a field of view of $24 \mathrm{~cm}$, and an acquisition matrix of $256 \times 256 \times 240$. A conjugate synthesis in combination with 
an interleaved acquisition resulted in 240 contiguous double-echo slices whose voxel dimensions were $0.94 \times 0.94 \times 0.9 \mathrm{~mm}$.

\section{Selection of TMS site}

The stimulation site was taken from a recent fMRI study that employed the same semantic and control tasks as the present study (Visser, Jefferies, Embleton, \& Lambon Ralph, 2011). This study revealed a large cluster of pMTG activation for the semantic over control task contrast, with a peak at $[-57,-42,-3]$ (see Figure 2). To locate this site in each participant, the target coordinates were converted from MNI space into each participant's native space using SPM5. Their T1-weighted scan was then coregistered with their scalp using an Ascension minibird magnetic tracking system and MRIreg software (http://www.cabiatl.com/mricro/mricro/mrireg/index.html) and the appropriate site marked on the scalp. Eight fiducial markers present during the scan (oil capsules attached to nasion, vertex, inion, tip of the nose, left/right mastoids, and left/right tragus during scanning) were used during the co-registration process.

A middle occipital stimulation site (occipital pole) was also employed as a site to control for possible non-specific visual effects and also for general arousal effects of TMS induced by somatosensory and acoustic artefacts. According to the international 10-20 electrode system, this site corresponds to the POz location.

\section{Stimulation parameters}

A MagStim Rapid2 (Magstim Co., Whitland, UK) stimulator with two external boosters was used (maximum output approx. 2.2 Tesla). Magnetic stimulation was applied using a 70-mm figure-of-eight coil. Individual motor threshold (MT) was determined for every participant prior to each session. Motor threshold was defined as a minimal intensity of stimulation capable of inducing contraction of the contralateral abductor

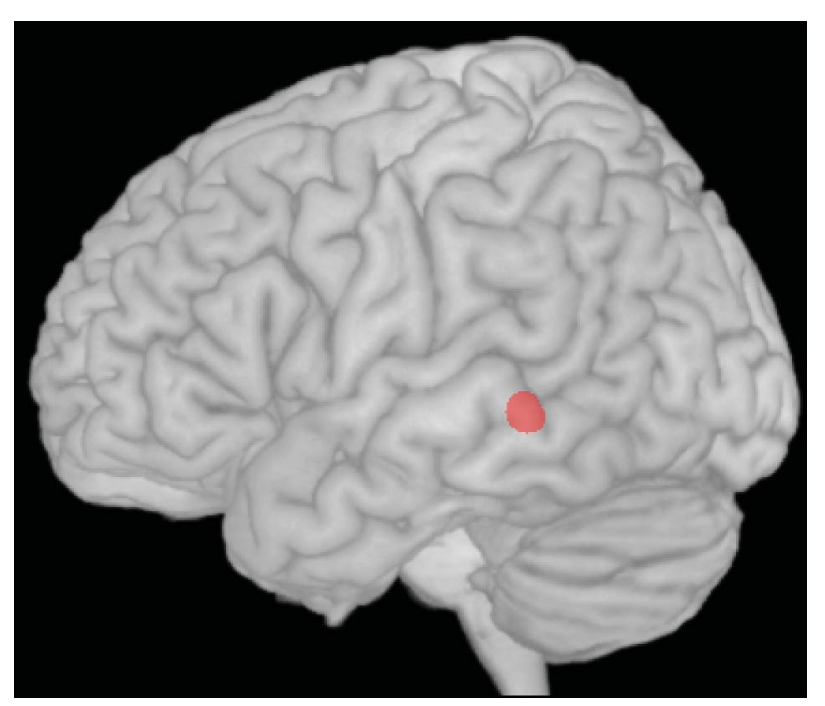

Figure 2. pMTG stimulation site $[-57-42-3]$. To view this figure in colour, please see the online issue of the journal. 
pollicis brevis muscle at the optimal scalp position. The average MT was $55 \%$ of the maximal stimulator output and the average stimulation intensity during rTMS was $63 \%$. Repetitive pulse TMS (rTMS) was delivered off-line for $10 \mathrm{~min}$ at $1 \mathrm{~Hz}(600 \mathrm{~s}$ at $120 \%$ motor threshold level) applied to either pMTG or occipital pole. This TMS protocol has been shown to produce behavioural effects that last at least 5 minutes following stimulation (Hilgetag, Theoret, \& Pascual-Leone, 2001; Kosslyn et al., 1999). Pilot testing indicated that most participants completed the experimental task within 5 minutes.

\section{RESULTS}

\section{Reaction times}

There were six stimuli for which fewer than $50 \%$ of participants responded correctly. These trials were excluded from all analyses. To analyse reaction times, outliers more two standard deviations longer than a participant's mean in any condition were excluded ( $5 \%$ of trials). There was no significant difference between scrambled pictures and scrambled words $(p>.05)$ so these were collapsed into a single control condition. Reaction times are shown in Figure 3. They were subjected to a $3 \times 2 \times 2$ repeated-measures ANOVA that included task, site, and TMS as within-participants factors. There were no main effects but there was a significant task $\times$ TMS interaction, $F(2,26)=14.4, p<.001$, and the site $\times$ TMS interaction approached significance, $F(1,13)=3.79, p=.073$. The task $\times$ TMS interaction occurred because participants reliably sped up on the control task following TMS, whereas no such effect was seen on semantic tasks. Performance on the control task was faster following stimulation of pMTG, $t(13)=3.21, p<.01$, and occipital pole, $t(13)=3.64, p<.01$. As this speeding effect was seen for both sites, it probably reflects a practice effect as a result of performing the task twice in a single session, rather than a specific effect of rTMS. There was no speeding for the semantic tasks. Instead, RTs to picture and word stimuli were

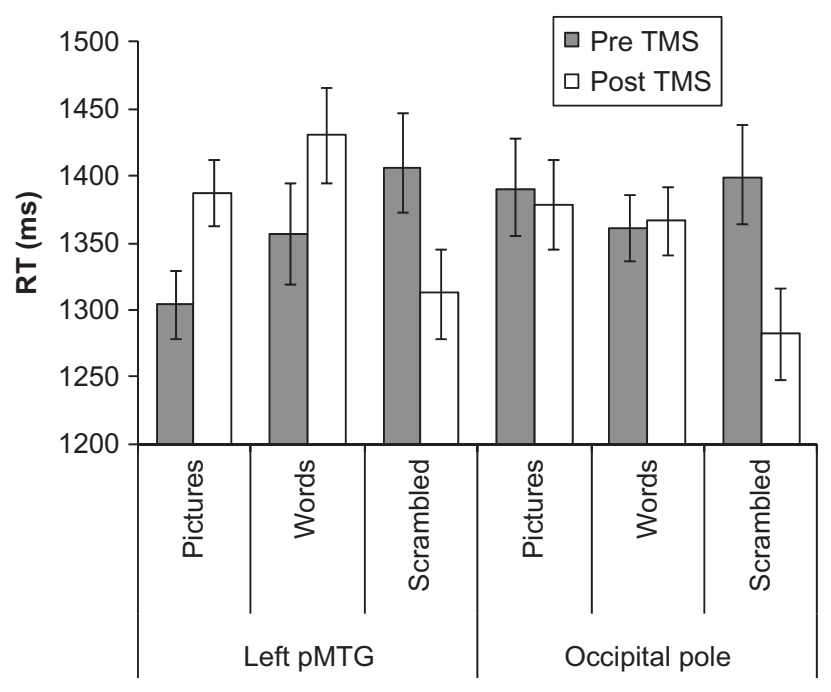

Figure 3. Reaction times before and after rTMS. Bars indicate standard error of mean, adjusted to reflect the between-condition variance used in repeated-measure designs (Loftus \& Masson, 1994). 


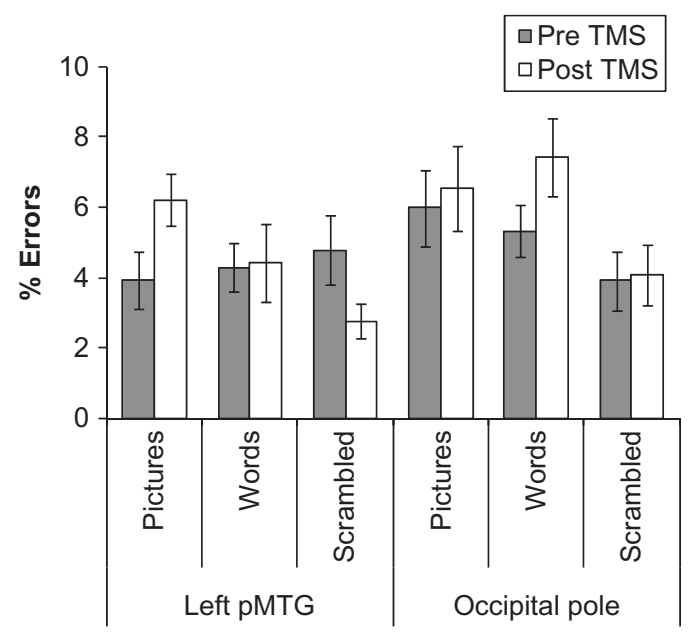

Figure 4. Error rates before and after rTMS. Bars indicate standard error of mean, adjusted to reflect the between-condition variance used in repeated-measure designs (Loftus \& Masson, 1994).

reliably slowed following pMTG stimulation: Pictures: $t(13)=2.38, p<.05$; Words: $t(13)=2.49, p<.05$. There was no slowing on these tasks following stimulation of the occipital pole $(p>.8)$.

\section{Errors}

Error rates are shown in Figure 4. A repeated-measures ANOVA was conducted with task, site and TMS (pre vs post-stimulation) as within-participants factors. This revealed a marginal main effect of task, $F(2,26)=3.35, p=.051$, and a main effect of site, $F(1,13)=9.05, p=.01$. The site effect was due to a higher error rate in the occipital pole conditions. However, there was no site $\times$ TMS interaction $(F<1, p>.5)$, indicating that this effect did not appear to be a consequence of stimulation. Instead this small difference could indicate uncontrolled fluctuation in participant motivation or performance across sessions. In addition, the task $\times$ TMS interaction approached significance, $F(2,26)=2.63, p=.091$. Post-hoc tests revealed that the task effect was due to a higher error rate for words than for pictures, $t(13)=3.46, p<.05$; neither semantic task differed from the control task. The effect of TMS on the picture task also approached significance for the $\mathrm{pMTG}$ site, $t(13)=1.97, p=.071$. There were no effects of TMS on error rates for the other tasks and no effects of occipital pole stimulation.

\section{DISCUSSION}

The left posterior middle temporal gyrus (pMTG) is an important area for semantic cognition (Binder et al., 2009; Cabeza \& Nyberg, 2000; Indefrey \& Levelt, 2004; Vigneau et al., 2006) but its function is a matter of debate. Although there is wide agreement that the region is key for lexical-semantic processing, it is not clear whether it also contributes to non-verbal semantic cognition. We used rTMS in healthy participants to investigate whether pMTG makes a necessary contribution to both verbal 
and non-verbal semantic processing. The results were unequivocal: pMTG stimulation slowed responses on verbal and non-verbal semantic tasks to an equal degree but had no such effect on difficulty-matched visual processing tasks.

These results are incompatible with the idea that pMTG is only involved in semantic processing when mapping between a word and its conceptual representation. Instead, pMTG appears to be a multimodal semantic region, necessary for both verbal and non-verbal semantic cognition. Our findings are in line with neuroimaging studies that have reported pMTG activation in purely non-verbal tasks (Kable et al., 2002; Kellenbach et al., 2003) and with neuropsychological studies that link pMTG damage with multimodal semantic deficits (Chertkow et al., 1997; Hart \& Gordon, 1990; Noonan et al., 2010). Additionally, these findings may help to explain the particular pattern of deficits that occurs in Wernicke's aphasia. Wernicke's aphasia has often been characterised as a disorder of acoustic-phonological processing but it has also long been known that many patients also often have non-verbal semantic deficits (Cohen, Kelter, \& Woll, 1980; De Renzi, Faglioni, Scotti, \& Spinnler, 1972; Gainotti, Silveri, Villa, \& Caltagirone, 1983). This has led some to propose a "dual-deficit" account in which the verbal comprehension deficit in these patients has both an acoustic-phonological component (due to damage to posterior superior temporal sulcus and gyrus) and a semantic component (due to pMTG damage; Baker, Blumstein, \& Goodglass, 1981; Hickok \& Poeppel, 2004). The present study confirms that pMTG makes a necessary contribution to non-verbal semantic cognition, suggesting that damage to this area is a plausible explanation for non-verbal semantic deficits in Wernicke's aphasia.

There are some limitations to the present study that should be noted. Participants were faster to perform the control task following TMS. Since this effect was observed both for pMTG and occipital pole stimulation, we interpret this as a practice effect rather than a genuine TMS effect. The mirror image matching task used as a control was unfamiliar and as such it is likely that participants improved over the course of the experiment. Such practice effects could be avoided in future studies by including a longer period of familiarisation with the task before beginning the main experiment, or by counterbalancing the order of stimulation such that some participants complete their baseline no-TMS condition after completing the TMS condition.

Moreover, although the present study highlights the multimodal role of pMTG in semantic cognition, many questions remain regarding its precise function. Some have suggested that pMTG is involved in the representation of motion or motor functions, making this region particularly important for the representation of tool and action knowledge (Campanella, D’Agostini, Skrap, \& Shallice, 2010; Devlin et al., 2002; Martin, 2007; Tranel et al., 2005). Another proposal holds that this area is part of a "semantic control" network that regulates access to semantic knowledge according to the demands of the current task or context (Jefferies \& Lambon Ralph, 2006; Noonan et al., 2010; Whitney, Jefferies, et al., 2011; Whitney, Kirk, et al., 2011). Either possibility is consistent with our data. The semantic association task is executively demanding because it requires a degree of problem solving to determine the relationship between probe and target. For example, when deciding whether camel goes with cactus or rose, overall similarity is not a good guide because camels share few features with either option. Instead, the participant must attend to one specific characteristic that camels and cacti have in common and ignore all other aspects of their semantic representations. Alternatively, the pMTG effect may have been observed because the majority of trials in the test featured manmade objects or required knowledge about how items 
interact (e.g., key with door; squirrel with acorn). A TMS effect would be expected if pMTG were involved in representing motions and actions associated with objects. Distinguishing between these putative functions of pMTG remains a target for future work. It is possible that different sub-regions within pMTG are involved in different elements of semantic cognition. rTMS is a particularly useful tool for investigating this possibility as it has a relatively high spatial resolution: divergent behavioural effects can be observed following stimulation to sites as little as $1 \mathrm{~cm}$ apart (Walsh \& Rushworth, 1999).

Another challenge is to understand the interaction of the pMTG with other regions in the wider semantic neural network. Converging evidence from neuroimaging (Binney, Embleton, Jefferies, Parker, \& Lambon Ralph, 2010; Devlin et al., 2000), rTMS (Pobric et al., 2007, 2010a) and from patients with semantic dementia (Bozeat et al., 2000; Mion et al., 2010) indicates that the anterior aspects of the temporal lobes are critical for representing concepts in multiple modalities. It has been suggested that anterior temporal regions act as a representational hub in which information from different sensory-motor modalities is integrated to form supra-modal conceptual representations (Lambon Ralph, Sage, Jones, \& Mayberry, 2010; Patterson et al., 2007; Rogers et al., 2004). This being the case, one possibility is that the temporal lobe forms a graded representational space (Plaut, 2002) in which the most anterior parts of the temporal lobes represent supra-modal conceptual information and there is a gradual shift towards modality-specific representation in more posterior temporal regions. A representational role for action/motion properties in pMTG would fit well in such a model. Further work is needed to achieve a better understanding the function of this area, particularly regarding its structural and functional connectivity within the semantic network. In any case, the present study suggests that a full account of pMTG function must include a role in non-verbal as well as verbal comprehension.

\section{REFERENCES}

Badre, D., Poldrack, R. A., Pare-Blagoev, E. J., Insler, R. Z., \& Wagner, A. D. (2005). Dissociable controlled retrieval and generalized selection mechanisms in ventrolateral prefrontal cortex. Neuron, 47(6), 907-918.

Badre, D., \& Wagner, A. D. (2007). Left ventrolateral prefrontal cortex and the cognitive control of memory. Neuropsychologia, 45(13), 2883-2901.

Baker, E., Blumstein, S. E., \& Goodglass, H. (1981). Interaction between phonological and semantic factors in auditory comprehension. Neuropsychologia, 19, 1-15.

Bedny, M., McGill, M., \& Thompson-Schill, S. L. (2008). Semantic adaptation and competition during word comprehension. Cerebral Cortex, 18, 2574-2585.

Binder, J. R., Desai, R. H., Graves, W. W., \& Conant, L. L. (2009). Where is the semantic system? A critical review and meta-analysis of 120 functional neuroimaging studies. Cerebral Cortex, 19, 2767-2796.

Binney, R. J., Embleton, K. V., Jefferies, E., Parker, G. J. M., \& Lambon Ralph, M. A. (2010). The inferolateral aspects of the anterior temporal lobe are crucial in semantic memory: Evidence from a novel direct comparison of distortion-corrected fMRI, rTMS and semantic dementia. Cerebral Cortex, 20, $2728-2738$.

Bozeat, S., Lambon Ralph, M. A., Patterson, K., Garrard, P., \& Hodges, J. R. (2000). Non-verbal semantic impairment in semantic dementia. Neuropsychologia, 38(9), 1207-1215.

Cabeza, R., \& Nyberg, L. (2000). Imaging cognition II: An empirical review of 275 PET and fMRI studies. Journal of Cognitive Neuroscience, 12, 1-47.

Campanella, F., D’Agostini, S., Skrap, M., \& Shallice, T. (2010). Naming manipulable objects: Anatomy of a category specific effect in left temporal tumours. Neuropsychologia, 48(6), 1583-1597.

Chertkow, H., Bub, D., Deaudon, C., \& Whitehead, V. (1997). On the status of object concepts in aphasia. Brain and Language, 58(2), 203-232. 
Cohen, R., Kelter, S., \& Woll, G. (1980). Analytical competence and language impairment in aphasia. Brain and Language, 10, 331-347.

Corbett, F., Jefferies, E., Ehsan, S., \& Lambon Ralph, M. A. (2009). Different impairments of semantic cognition in semantic dementia and semantic aphasia: Evidence from the non-verbal domain. Brain, 132, 2593-2608.

De Renzi, E., Faglioni, P., Scotti, G., \& Spinnler, H. (1972). Impairment in associating colour to form, concomitant with aphasia. Brain, 95, 293-304.

Devlin, J. T., Jamison, H. L., Gonnerman, L. M., \& Matthews, P. M. (2006). The role of the posterior fusiform gyrus in reading. Journal of Cognitive Neuroscience, 18(6), 911-922.

Devlin, J. T., Moore, C. J., Mummery, C. J., Gorno-Tempini, M. L., Phillips, J. A., Noppeney, U., et al. (2002). Anatomic constraints on cognitive theories of category specificity. NeuroImage, 15(3), 675-685.

Devlin, J. T., Russell, R. P., Davis, M. H., Price, C. J., Wilson, J., Moss, H. E., et al. (2000). Susceptibilityinduced loss of signal: Comparing PET and fMRI on a semantic task. NeuroImage, 11(6), 589-600.

Dronkers, N. F., Wilkins, D. P., Van Valin, R. D., Redfern, B. B., \& Jaeger, J. J. (2004). Lesion analysis of the brain areas involved in language comprehension. Cognition, 92(1-2), 145-177.

Gainotti, G., Silveri, M. C., Villa, G., \& Caltagirone, C. (1983). Drawing objects from memory in aphasia. Brain, 106, 613-622.

Gold, B. T., Balota, D. A., Jones, S. J., Powell, D. K., Smith, C. D., \& Andersen, A. H. (2006). Dissociation of automatic and strategic lexical-semantics: Functional magnetic resonance imaging evidence for differing roles of multiple frontotemporal regions. Journal of Neuroscience, 26, 6523-6532.

Gough, P. M., Nobre, A. C., \& Devlin, J. T. (2005). Dissociating linguistic processes in the left inferior frontal cortex with transcranial magnetic stimulation. Journal of Neuroscience, 25(35), 8010-8016.

Hart, J., \& Gordon, B. (1990). Delineation of single-word semantic comprehension deficits in aphasia with anatomical correlation. Annals of Neurology, 27, 226-231.

Hickok, G., \& Poeppel, D. (2004). Dorsal and ventral streams: A framework for understanding aspects of the functional anatomy of language. Cognition, 92(1-2), 67-99.

Hickok, G., \& Poeppel, D. (2007). The cortical organization of speech processing. Nature Reviews Neuroscience, 8(5), 393-402.

Hilgetag, C. C., Theoret, H., \& Pascual-Leone, A. (2001). Enhanced visual spatial attention ipsilateral to rTMS-induced 'virtual lesions' of human parietal cortex. Nature Neuroscience, 4(9), 953-957.

Holland, R., \& Lambon Ralph, M. A. (2010). The anterior temporal lobe semantic hub is a part of the language neural network: Selective disruption of irregular past tense verbs by rTMS. Cerebral Cortex, 20(12), 2771-2775.

Howard, D., \& Patterson, K. (1992). Pyramids and Palm Trees: A test of semantic access from pictures and words. Bury St Edmunds, UK: Thames Valley Test Company.

Indefrey, P., \& Levelt, W. J. M. (2004). The spatial and temporal signatures of word production components. Cognition, 92(1-2), 101-144.

Jefferies, E., \& Lambon Ralph, M. A. (2006). Semantic impairment in stroke aphasia vs. semantic dementia: A case-series comparison. Brain, 129, 2132-2147.

Kable, J. W., Lease-Spellmeyer, J., \& Chatterjee, A. (2002). Neural substrates of action event knowledge. Journal of Cognitive Neuroscience, 14(5), 795-805.

Kellenbach, M. L., Brett, M., \& Patterson, K. (2003). Actions speak louder than functions: The importance of manipulability and action in tool representation. Journal of Cognitive Neuroscience, 15(1), 30-46.

Kherif, F., Josse, G., \& Price, C. J. (2011). Automatic top-down processing explains common left occipitotemporal responses to visual words and objects. Cerebral Cortex, 21(1), 103-114.

Kosslyn, S. M., Pascual-Leone, A., Felician, O., Camposano, S., Keenan, J. P., Thompson, W. L., et al. (1999). The role of Area 17 in visual imagery: Convergent evidence from PET and rTMS. Science, 284(5411), 167-170.

Lambon Ralph, M. A., Sage, K., Jones, R., \& Mayberry, E. (2010). Coherent concepts are computed in the anterior temporal lobes. Proceedings of the National Academy of Sciences of the United States of America, 107, 2717-2722.

Leff, A. P., Schofield, T. M., Crinion, J. T., Seghier, M. L., Grogan, A., Green, D. W., et al. (2009). The left superior temporal gyrus is a shared substrate for auditory short-term memory and speech comprehension: Evidence from 210 patients with stroke. Brain, 132, 3401-3410.

Loftus, G. R., \& Masson, M. E. J. (1994). Using confidence-intervals in within-subject designs. Psychonomic Bulletin \& Review, 1(4), 476-490.

Martin, A. J. (2007). The representation of object concepts in the brain. Annual Review of Psychology, 58, $25-45$. 
Mion, M., Patterson, K., Acosta-Cabronero, J., Pengas, G., Izquierdo-Garcia, D., Hong, Y. T., et al. (2010). What the left and right fusiform gyri tell us about semantic memory. Brain, 133, 3256-3268.

Noonan, K. A., Jefferies, E., Corbett, F., \& Lambon Ralph, M. A. (2010). Elucidating the nature of deregulated semantic cognition in semantic aphasia: Evidence for the roles of the prefrontal and temporoparietal cortices. Journal of Cognitive Neuroscience, 22, 1597-1613.

Noppeney, U., Phillips, J., \& Price, C. (2004). The neural areas that control the retrieval and selection of semantics. Neuropsychologia, 42, 1269-1280.

Patterson, K., Nestor, P. J., \& Rogers, T. T. (2007). Where do you know what you know? The representation of semantic knowledge in the human brain. Nature Reviews Neuroscience, 8(12), 976-987.

Plaut, D. C. (2002). Graded modality-specific specialisation in semantics: A computational account of optic aphasia. Cognitive Neuropsychology, 19(7), 603-639.

Pobric, G., Jefferies, E., \& Lambon Ralph, M. A. (2007). Anterior temporal lobes mediate semantic representation: Mimicking semantic dementia by using rTMS in normal participants. Proceedings of the National Academy of Sciences of the United States of America, 104(50), 20137-20141.

Pobric, G., Jefferies, E., \& Lambon Ralph, M. A. (2010a). Amodal semantic representations depend on both anterior temporal lobes: Evidence from repetitive transcranial magnetic stimulation. Neuropsychologia, 48, 1336-1342.

Pobric, G., Jefferies, E., \& Lambon Ralph, M. A. (2010b). Category-specific vs. category-general semantic impairment induced by transcranial magnetic stimulation. Current Biology, 20, 964-968.

Price, C. J., \& Friston, K. J. (2002). Degeneracy and cognitive anatomy. Trends in Cognitive Sciences, 6(10), 416-421.

Rodd, J. M., Davis, M. H., \& Johnsrude, I. S. (2005). The neural mechanisms of speech comprehension: fMRI studies of semantic ambiguity. Cerebral Cortex, 15(8), 1261-1269.

Rogers, T. T., Lambon Ralph, M. A., Garrard, P., Bozeat, S., McClelland, J. L., Hodges, J. R., et al. (2004). Structure and deterioration of semantic memory: A neuropsychological and computational investigation. Psychological Review, 111(1), 205-235.

Saygin, A. P., Dick, F., Wilson, S. M., Dronkers, N., \& Bates, E. (2003). Neural resources for processing language and environmental sounds. Brain, 126, 928-945.

Thompson-Schill, S. L., D’Esposito, M., Aguirre, G. K., \& Farah, M. J. (1997). Role of left inferior prefrontal cortex in retrieval of semantic knowledge: A reevaluation. Proceedings of the National Academy of Sciences of the United States of America, 94, 14792-14797.

Tranel, D., Martin, C., Damasio, H., Grabowski, T. J., \& Hichwa, R. (2005). Effects of noun-verb homonymy on the neural correlates of naming concrete entities and actions. Brain and Language, 92(3), 288-299.

Turken, A. U., \& Dronkers, N. F. (2011). The neural architecture of the language comprehension network: Converging evidence from lesion and connectivity analyses. Frontiers in Systems Neuroscience, 5(1). doi:10.3389/fnsys.2011.00001.

Vigneau, M., Beaucousin, V., Hervé, P. Y., Duffau, H., Crivello, F., Houdé, O., et al. (2006). Meta-analyzing left hemisphere language areas: Phonology, semantics and sentence processing. NeuroImage, 30 , 1414-1432.

Visser, M., Jefferies, E., Embleton, K. V., \& Lambon Ralph, M. A. (2011). Evidence for a caudo-rostral gradient of information convergence in the temporal lobes: An fMRI study of verbal and non-verbal semantic processing. Manuscript submitted for publication.

Visser, M., Jefferies, E., \& Lambon Ralph, M. A. (2010). Semantic processing in the anterior temporal lobes: A meta-analysis of the functional neuroimaging literature. Journal of Cognitive Neuroscience, 22, 1083-1094.

Walsh, V., \& Cowey, A. (2000). Transcranial magnetic stimulation and cognitive neuroscience. Nature Reviews Neuroscience, 1(1), 73-79.

Walsh, V., \& Rushworth, M. (1999). A primer of magnetic stimulation as a tool for neuropsychology. Neuropsychologia, 37, 125-135.

Whitney, C., Jefferies, E., \& Kircher, T. (2011). Heterogeneity of the left temporal lobe in semantic representation and control: Priming multiple vs. single meanings of ambiguous words. Cerebral Cortex, 21, 831-844.

Whitney, C., Kirk, M., O’Sullivan, J., Lambon Ralph, M. A., \& Jefferies, E. (2011). The neural organization of semantic control: TMS evidence for a distributed network in left inferior frontal and posterior middle temporal gyrus. Cerebral Cortex, 21(5), 1066-1075.

Wise, R. J. S., Scott, S. K., Blank, S. C., Mummery, C. J., Murphy, K., \& Warburton, E. A. (2001). Separate neural subsystems within 'Wernicke's area'. Brain, 124, 83-95. 